\title{
LA CONCEPTUALIZACIÓN DE LA MENTIRA EN TIEMPOS DE LA POSVERDAD
}

\author{
Juan Antonio González de Requena Farré* \\ doi: 10.11144/Javeriana.uph36-72.cmtp
}

\begin{abstract}
RESUMEN
Este artículo se propone sistematizar distintas opciones de conceptualización de la mentira para así clarificar el sentido de la posverdad contemporánea. Ante las limitaciones de la reconstrucción histórica de las acepciones de la mentira legadas por la tradición filosófica y debido a que el análisis conceptual corre el riesgo de fetichizar la afirmación mentirosa, apostamos por enriquecer la conceptualización de la mentira a través de la descripción lexicográfica del sentido prototípico y de las variantes del vocabulario idiomático de la mentira. Al distinguir las condiciones formales del decir una mentira y los matices situacionales de la realización del mentir, se puede reconocer en la posverdad contemporánea un nuevo régimen de la mentira.
\end{abstract}

Palabras clave: mentira; veracidad; sinceridad; posverdad

Universidad Austral de Chile, Puerto Montt, Chile.

Correo electrónico: jgonzalez@spm.uach.cl

Para citar este artículo: González de Requena Farré, J. A. (2019). La conceptualización de la mentira en tiempos de la posverdad. Universitas Philosophica, 36(72), 97-123. ISSN 0120-5323, ISSN en línea 2346-2426. doi: 10.11144/Javeriana.uph36-72.cmtp 


\title{
THE CONCEPTUALIZATION OF LYING IN THE TIMES OF POST-TRUTH
}

\begin{abstract}
This article aims to systematize different alternatives for the conceptualization of lying, in order to clarify the meaning of contemporary posttruth. Given the limitations of a historical reconstruction of the meanings of lying devised by the philosophical tradition, and because conceptual analysis risks of fetishizing the lying assertion, we aim to enrich the conceptualization of lying through the lexicographical description of the prototypical sense and the variants of our idiomatic vocabulary for lying. By distinguishing the formal conditions of telling a lie and the situational nuances of the realization of lying, one can recognize a new regime of lies in contemporary post-truth.
\end{abstract}

Keywords: lying; truthfulness; sincerity; post-truth 
CORREN TIEMPOS PROPICIOS para los embustes, los infundios, las patrañas, los sofismas, los bulos y las paparruchas. Incluso es posible que estemos asistiendo a la irrupción de nuevas formas de falsificación verbal intencionada, como pone de manifiesto el reciente neologismo posverdad. En 2016, la palabra post-truth fue elegida palabra del año por Oxford Dictionaries, como concepto que designa los contextos en que los hechos son menos importantes para la opinión pública que la apelación a las emociones o a las creencias personales, de manera que el discurso pierde la capacidad de referencia factual o de enunciación veritativa. En la creciente bibliografía sobre la posverdad, se considera que este término designa un fenómeno no tan nuevo, consistente en propalar falsedades bajo la forma de noticias publicadas en las redes sociales, ya sea por bromear, por ideología o solo por añadir contactos. Podría tratarse, pues, de una forma de charlatanería (bullshit) que provee invenciones, representaciones distorsionadas, medias verdades, bulos y algo de escándalo, con indiferencia a la veracidad, sin preocupación por la deshonestidad e, incluso, mediante una mitigación eufemística del mentir (que se justifica defensivamente como la enunciación de hechos alternativos, según la expresión acuñada en el círculo del presidente norteamericano y maestro de la posverdad, Donald Trump) (Ball, 2017; Keyes, 2004).

Este tránsito a una situación de posverdad puede atribuirse a la erosión de los vínculos y obligaciones comunitarios, sin los cuales el interés egoísta no encuentra reparos en recurrir a la mentira. Asimismo, contribuyen a la posverdad el encumbramiento de la impostura en algunas prácticas profesionales y círculos intelectuales, la gran escala de la fabricación de falsedades y circulación de medias verdades en los medios de comunicación de masas, el incentivo mediático a la ficción y la desinformación, el protagonismo concedido a los farsantes y los tramposos en los medios, así como las nuevas formas de engaño tecnológicamente asistido y de mentira virtualizada en la Web y en las redes sociales (Keyes, 2004). Por último, la consolidación de la posverdad contemporánea resulta inseparable de la actual alienación informativa de los públicos, ya que, al aislarse las personas en círculos, redes sociales y comunidades virtuales acotadas, se generan burbujas informacionales que operan como compartimientos ideológicos en los cuales solo se refuerzan las propias creencias y la desinformación en común, sin oportunidad de rastrear las fuentes primarias de los bulos - consumidos como información viral- ni de contrastar las versiones difundidas en sitios fraudulentos 
de la Web (Cooke, 2017). Cabría pensar que en la sociedad contemporánea se ha consolidado cierto régimen de posverdad sustentado en la segmentación de los mercados informacionales, en la circulación mediática masiva de noticias no contrastadas, en la seudoparticipación expresiva en las redes sociales, en el consumo dirigido de contenidos administrados mediante algoritmos de la ingeniería de datos y, en última instancia, en la multiplicación de las burbujas informacionales y los entornos discursivos autorreferentes (Harsin, 2015). Quizás, podríamos considerar que no hay nada nuevo bajo el sol, y que la posverdad no es sino un término distractor y engañoso que encubre la mentira en el espacio público contemporáneo (Cruz, 2017); sin embargo, para dirimir la cuestión, resulta preciso disponer de un análisis riguroso de las condiciones y modalidades de la mentira.

En las dos primeras secciones del artículo, realizaremos una revisión teórica del estado del arte tradicional y de los acercamientos lógico-lingüísticos contemporáneos a la mentira, con el propósito de rescatar cierta distinción entre decir una mentira (o la mentira del enunciado) y mentir (la mentira de la enunciación). Esa distinción nos permitirá desbordar el análisis de las condiciones necesarias y suficientes de la declaración de una mentira, de modo que podamos disponer de una perspectiva plural y gradual del mentir, más allá de la consideración aislada del enunciado mentiroso. La tercera sección da cuerpo a nuestra concepción ampliada del mentir, a través de la descripción lexicográfica y de una fenomenología lingüística de las acepciones cotidianas de la mentira. Con esa redescripción y reencuadre de la mentira de la enunciación, que introduce condiciones y marcos prototípicos, resulta posible discutir si la llamada posverdad constituye un tipo de posmentira o metamentira, como proponemos en la conclusión.

\section{Concepciones de la mentira en la tradición filosófica}

LA TRADICIÓN FILOSÓFICA proporciona una valiosa guía para abordar el problema de la mentira. San Agustín articuló cierta concepción tradicional de la mentira, al asociar el mentir a dos condiciones: a) cierta duplicidad en el pensamiento, esto es, pensar algo que se sabe u opina que es verdad y, por otro lado, expresar otra cosa distinta mediante la palabra u otros signos, pensando o sabiendo que es falso lo que se dice; b) el deseo intencionado o la voluntad de engañar (San Agustín, 
1954, pp. 533-535). En ese sentido, no se mentiría al decir algo falso que se cree o piensa que es verdadero, pero sí habría mentira si decimos algo verdadero que creemos falso. Tampoco hay mentira cuando se habla en broma o en sentido figurado. En cuanto a la intención de engañar, constituye una condición de la mentira, aun cuando no logremos engañar efectivamente; más difícil resulta decidir si se miente cuando decimos algo falso o inverosímil para no engañar al interlocutor, o bien cuando alguien sin credibilidad dice algo que considera verdadero, para inducir a otros a creer en su falsedad. Según San Agustín (1954, pp. 535-539), lo indudable es que miente de modo manifiesto quien voluntariamente dice algo falso con intención de engañar, independientemente de la utilidad que pueda tener la mentira o del provecho para el que miente, para aquel a quien se miente o para terceras personas. Por consiguiente, para no mentir habría que limitarse a afirmar conscientemente lo que creemos o sabemos que es verdad, con el propósito de persuadir o convencer únicamente de lo que hemos dicho.

A la hora de clasificar los tipos de mentiras, San Agustín sí contempla las motivaciones del mentiroso: a) existen mentiras que perjudican a otros, como las mentiras capitales en materia religiosa (que no convienen espiritualmente a nadie); b) las mentiras que dañan a alguien sin provecho para nadie; c) las mentiras que favorecen a alguien pero perjudican a otro; d) hay mentiras puras, o sea, la mendacidad del que miente solo por el deleite de engañar (a diferencia del embustero ocasional); e) hay mentiras que intentan embelesar en la conversación; asimismo, f) cabe reconocer un tipo de mentiras honestas que no dañan a nadie y favorecen a alguien (como decir que no se sabe algo a alguien que nos pregunta para cometer una falta) o intentan convertirlo a la fe; o bien g) mentiras que no perjudican a nadie y son provechosas para una tercera persona (como cuando se miente al asesino para salvar a su víctima); finalmente, h) existe un tipo de mentira que a nadie perjudica y permite que una persona no sea mancillada, corporalmente violentada o sumida en la inmundicia (San Agustín, 1954, pp. 565577). Pese a la sutil distinción entre las modalidades de la mentira, San Agustín concluye categóricamente que no se ha de intentar mentir de ninguna manera, aunque se peca más en las primeras clases de mentira, y se peca menos cuanto más nos acercamos al último tipo de mentira (San Agustín, 1954, pp. 603-606).

La reflexión moderna mantuvo la convicción moral de que la mentira se vincula al intento de engañar, pero generalmente tuvo más consideración con las 
condiciones subjetivas de la mentira que con la condena incondicional del mentir como pecado. En Montaigne, la mentira resulta descrita como una condición de una época sumida en la simulación, la vanidad y el embuste, pero también como una propensión subjetiva de los seres humanos, indecisos al defenderse del engaño y prestos a dejarse engañar por el orgullo, por su debilidad anímica interior y por la experiencia externa. Sin embargo, Montaigne condena la mentira tanto por su falta a la veracidad y por la doble ofensa infligida a la dignidad de quien se sirve de la mentira y a la de la persona a quien se miente, como por el hecho de que el falseamiento de la palabra traiciona la vida pública, arruina el conocimiento común y la comunicación, y destruye el lazo social (Montaigne, 1998, pp. 418-419). Las reflexiones de Montaigne sobre la mentira son particularmente afortunadas cuando el ensayista francés recoge cierta distinción entre decir una mentira y mentir, así como al reconocer que, a diferencia de la verdad -que es única-, la mentira tiene muchas facetas y un campo infinito de posibilidades. En ese sentido, según Montaigne, quien dice una mentira dice algo falso que ha tomado por verdadero; el que miente contraviene a su conciencia, pues habla contra lo que sabe, ya sea al inventar todo, o bien al disfrazar o alterar el fondo verdadero de las cosas. En otras palabras, al decir una mentira se enuncia una falsedad, pero al mentir se finge, esconde o distorsiona el conocimiento verdadero, de manera que las opciones de la mentira son múltiples (Montaigne, 1992, pp. 69-73).

En el caso de Grocio, la reflexión moderna sobre las condiciones de la mentira se concentra en las formas en que se compromete el derecho subjetivo -naturalmente otorgado y socialmente respetado- a juzgar por sí mismo. Grocio distingue el engaño mediante la simulación y la mentira en tanto que dolo ejercido al significar con la palabra. En rigor, quien miente dice a sabiendas algo, pero significa otra cosa distinta de lo que concibe en su mente. No mentiría el que dice una falsedad que considera verdad, sino quien dice algo verdadero que juzga falso (Grocio, 1925, pp. 279-285). Desde esa perspectiva, tampoco hay mentira cuando se emplea un lenguaje ambiguo o figurativo, de modo que hay varias significaciones en juego. Cuando el contexto comunicativo exige precisión y claridad respecto a lo que se significa, también podría considerarse que hay mentira en sentido lato cuando se emplean locuciones oscuras, si la expresión no puede entenderse en un sentido distinto del concebido por el locutor (Grocio, 1925, pp. 286-287). 
Sin embargo, Grocio introduce una restricción adicional para que pueda hablarse de mentira: solo hay mentira cuando se infringe el derecho de aquel con quien nos comunicamos; en concreto, si afectamos la libertad para juzgar que se presupone en nuestros interlocutores y que nos obliga mutuamente (Grocio, 1925, pp. 289-290). Grocio considera que ese derecho a juzgar, impugnado por la mentira, puede suspenderse por consentimiento expreso o por conflicto con derechos más relevantes. Por eso, no se puede culpar de mentir a quien significa algo falso a un niño o un demente, que carecen de libertad de juicio que pueda ser dañada; tampoco hay mentira cuando un tercero distinto de nuestro interlocutor se engaña al oír casualmente nuestra conversación, ya que no hay obligaciones con él; asimismo, no puede hablarse de mentira si afectamos la libertad de juicio de nuestro interlocutor para un mayor provecho suyo o por su bien, cuando se preserva la vida de alguien o se evita un crimen, o bien cuando mentimos al enemigo; ni es cuestionable que diga falsedades quien tiene un derecho superior al de los interlocutores, en virtud de su autoridad (Grocio, 1925, pp. 290-297).

Frente a esta casuística moderna de las condiciones en que hay que hacer valer el derecho subjetivo a juzgar por sí mismo de nuestro interlocutor, Kant restauró una condena moral categórica de la mentira, y consideró ilegítimo mentir en cualquier caso, incluso en aquellas situaciones en que la mentira pueda resultar provechosa. $Y$ es que la máxima de mentir no puede convertirse en ningún caso en ley universal sin autodestruirse, puesto que, si se asume como principio universal la mentira, se acabaría con la posibilidad de decir la verdad y la opción misma de mentir; de ese modo, se atacaría el principal deber moral del hombre hacia sí mismo, la veracidad, así como se socavaría la dignidad inherente de seres racionales y libres que son fines en sí mismos (Kant \& Constant, 2012, pp. 5-8, 37-41). Pese a la réplica de Constant en el sentido de que decir la verdad no es un principio universal (pues hay que barajar principios intermediarios de aplicación, como que solo es un deber decir la verdad para quien tiene derecho a ella, y no en aquellas situaciones en que perjudica a otros), Kant defendió estrictamente el carácter absoluto del deber de decir la verdad y rechazó categóricamente que exista algún derecho a mentir por filantropía o en virtud de alguna excepción a los principios derivada de algún principio intermediario o alguna circunstancia de aplicación (Kant \& Constant, 2012, pp. 9-23, 25-36). Por eso, Kant pudo 
definir la mentira al margen de cualquier casuística utilitaria y sin incluir el potencial perjuicio o daño sobre otra persona: "como una declaración intencionalmente no verdadera hecha a otro hombre" (Kant \& Constant, 2012, p. 29). Semejante caracterización de la mentira vuelve a introducir como condiciones aquellos aspectos que San Agustín ya consideró propios del mentir (y que han articulado la concepción tradicional de la mentira), a saber: la intencionalidad deliberada de la falsedad y, además, la falta de veracidad.

El dilema moral en torno a la mentira, esto es, si la mentira ha de ser excluida por principio o se han de considerar sus consecuencias, ha proseguido en la filosofía contemporánea. A partir de la tradicional concepción de la mentira como mensaje intencionalmente engañoso transmitido bajo la forma de un enunciado, Bok (1979) exploró las discrepancias entre las perspectivas del mentiroso y del engañado, en la medida en que ambos puntos de vista generan sesgos morales, y recomendó alternar ambos tipos de consideraciones. Desde el punto de vista del engañado, la mentira se traduce en coerción y, consecuentemente, en resentimiento, desconfianza y sospechas, que pueden incluso proyectarse hacia el pasado y desalentar respecto a las opciones de futuro; también puede afectar a terceros. Desde la perspectiva del mentiroso, la mentira podría parecer un recurso si se emplea hábilmente; no en vano, el engañador se posiciona como un oportunista que prefiere ampliar sus ventajas al engañar, antes que ser engañado, pero ignora el daño que se hace a sí mismo, a su propia integridad, a la confianza pública y a la vida social (Bok, 1979, pp. 18-33).

Frente a este tipo de consideraciones relativas a las consecuencias de la mentira, Shiffrin (2014) señala que la incorrección de la mentira resulta intrínseca y asume una posición de principios al considerar el nexo entre comunicación discursiva e iniciativa moral. En ese sentido, la sinceridad y la veracidad comunicativas constituirían prioridades morales sustantivas para proteger la confiabilidad comunicativa y las condiciones de la acción moral. La mentira compromete la autocomprensión del agente con testimonios no confiables, y falla cuando hay que tratar a los otros como pares morales y personas racionales; pero, además, el mentiroso se aísla de una relación moral basada en la comunicación racional y afecta a la humanidad, al obrar bajo una máxima que no puede universalizarse ni servir como principio público de acción, pues compromete el acceso confiable a la verdad, la confiabilidad racional de nuestras justificaciones y la persecución 
común de metas morales asociadas a la comprensión mutua y la cooperación social (Shiffrin, 2014, pp. 1-2).

\section{Análisis lógico-lingüísticos de las condiciones de la mentira en el pensamiento contemporáneo}

El ANÁlisis FILOSÓFICO CONTEMPORÁNEO del concepto de mentira ha discutido profusamente las condiciones necesarias y suficientes que se hacen presentes en la definición tradicional, a saber: decir un enunciado considerado falso por el hablante y dirigirse a otra persona, con la intención de que esta crea que el enunciado es verdadero. En principio, la definición tradicional de la mentira contiene cuatro condiciones: la formulación de un enunciado, la creencia por parte del hablante en que el enunciado es falso o no veraz, la presencia de un destinatario a quien se dirige la mentira y, finalmente, la intención de engañar al destinatario (Mahon, 2015). Según Mahon, los principales análisis filosóficos de la mentira se diferencian por la aceptación o no de ese conjunto de condiciones. Existen posiciones que consideran necesaria la intención de engañar (deceptionism), ya sea porque exigen que se dé un enunciado no veraz con intención de engañar (simple deceptionism), porque contemplan el requisito de que se realice una aserción no veraz con la intención de engañar mediante la quiebra de la confianza mutua (complex deceptionism), o bien porque sostienen que la mentira es un enunciado no veraz con intención de engañar que involucra la violación o agravio del derecho moral de otra persona (moral deceptionism). En otros análisis de la mentira, no se considera necesaria para que haya mentira la condición de que alguien intente engañar (non-deceptionism): en algunos casos, se asume que, para que haya mentira, basta con que haya una enunciación no veraz (simple non-deceptionism); en otros, se exige que, además de formularse un enunciado no veraz, se dé la garantía de la verdad de lo enunciado o de la afirmación no veraz (complex non-deceptionism) (Mahon, 2015).

Por su parte, Meibauer (2018) considera que actualmente existen distintas estrategias a la hora de definir la mentira: se puede integrar en el concepto de mentira la intención de engañar por parte del locutor; cabe definir la mentira como una aserción insincera (afirmar algún contenido proposicional sin creerlo); al definir la mentira, se puede evitar el concepto de engaño y de aserción, y 
apelar a la pretensión de garantizar la verdad; por último, existe la posibilidad de definir la mentira como una infracción de cierta máxima conversacional que nos exige que nuestra contribución sea verdadera, y no decir nada que creamos falso (Meibauer, 2018).

Esta gama de perspectivas analíticas frente al concepto de mentira no solo asume distintas posiciones ante las condiciones de la definición tradicional, sino que también intenta dar respuesta a algunos contraejemplos que cuestionan las condiciones tradicionales y, particularmente, la intencionalidad de engañar. En la mentira descarada (bald-faced lie), es de público conocimiento que el hablante no cree que es verdad lo que dice, como ocurre cuando un testigo miente en un tribunal por miedo a las represalias, aun cuando ya se ha probado suficientemente la culpabilidad del acusado. En el caso de ciertas mentiras relativas al conocimiento (knowledge-lies), la persona no miente para inducir disimuladamente una creencia falsa y engañar a alguien, sino solo para que alguien no tome conocimiento de cierta información, tal y como sucedería si tratamos de evitar que se identifique a alguien de un grupo, diciendo que todos somos esa persona. También cabe concebir mentiras más sofisticadas relativas al conocimiento, como aquellas en que se niega que se sabe algo de lo que se tiene conocimiento (metaknowledge-lies), esas en que se impugna el conocimiento común presupuesto en la acción grupal (common-knowledge lies), o bien aquellas en que no se reconoce públicamente lo que se sabe (acknowledgement-lies) (Sorensen, 2010).

Cabría pensar que la mentira es multiforme: se puede mentir simplemente al decir una falsedad; pero también hay metamentiras (al desmentir lo que se dijo o sostener que no se dijo algo con la intención de mentir), mentiras basadas en la explotación de los presupuestos implícitos o en alguna implicatura conversacional engañosa (al decir algo verdadero que lleva al oyente a inferir algo falso, como ocurre cuando alguien afirma que actualmente no tiene deudas, para que el oyente infiera falsamente que nunca las tuvo); asimismo, cabría concebir mentiras basadas en la supresión de evidencia de nuestro relato calculado de los hechos, o bien mentiras que se aprovechan de la imprecisión de las significaciones lingüísticas (D’Agostini, 2013, p. 11).

Por si fuera poco, se han caracterizado formas de engaño verbal muy semejantes a la mentira: las paparruchas (bumbug) consistirían en tergiversaciones engañosas a través de palabras u obras pomposas o artificiales (sin decir explícitamente 
una mentira) que falsifican la posición del hablante respecto a sus pensamientos, sentimientos o actitudes (Black, 1982); por otra parte, la charlatanería (bullshit) ha sido descrita como una modalidad de engaño verbal que falsifica la intención comunicativa, al hablar fraudulentamente sin que importen los valores veritativos (a diferencia de la mentira, que presupone la guía de la verdad para enunciar deliberadamente una falsedad) (Frankfurt, 2006).

Ante el complejo panorama de contraejemplos y variantes de la mentira, en los análisis filosóficos contemporáneos ha habido diferentes modos de reformular las condiciones asociadas al mentir. Uno de los análisis más reconocidos, el de Chisholm y Feehan (1977), sostiene que el hablante miente a un oyente si hay un contenido proposicional $p$ que el hablante cree que no es verdadero (o cree que es falso), y el hablante realiza la afirmación (asserts) de que $p$ al oyente. En ese sentido, afirmar no solo implica a) declarar algo, creyendo que la expresión significa $p$ en cierto idioma, y usar la expresión para intentar que el oyente crea que el hablante intentó emplearla del modo usual, sino también b) declararlo en condiciones tales que el oyente crea que el hablante cree $p$, lo acepta, e intenta causar que el oyente crea en la aceptación de $p$ por parte del hablante. Este análisis de la mentira endurece las condiciones de la enunciación, al exigir una afirmación (assertion) que asegura y hace valer cierto contenido proposicional. Desde ese punto de vista, aunque la condición de engaño no quede recogida en la definición de mentira, se supone que mentir implica un engaño directo y positivo, que intenta causar la adquisición de una creencia (más que limitarse a contribuir al mantenimiento de la creencia o procurar que se deje de creer); pero también involucra cierto quiebre de la confianza y una impugnación del derecho del oyente a esperar que el hablante acepte lo que dice (Chisholm \& Feehan, 1977). En fin, la posición de Chisholm y Feehan corresponde a una concepción compleja del carácter engañoso de la mentira (complex deceptionism), que también introduce elementos de una perspectiva moral en la medida en que pondera los derechos del oyente (moral deceptionism) (Mahon, 2015).

Algunos análisis de la mentira han insistido en que esta involucra no solo un intento de engañar, sino también un ejercicio de manipulación, al suministrar información engañosa en una situación de dependencia informativa respecto a quien habla. En el análisis de Faulkner (2007), el mentiroso lleva a cabo un doble engaño, pues engaña sobre cierta cuestión de hecho, al afirmar algo que considera 
falso; pero, además, engaña al pretender ser sincero ante los oyentes y al procurar que su enunciado sea aceptado porque él lo dice, en la medida en que los oyentes asuman que él intenta que crean lo que dice, lo crean sincero y tomen su sinceridad como razón para creerle. Así, el mentiroso invoca la confianza de unos oyentes que se encuentran en situación de dependencia informacional del enunciador; pretende que los oyentes crean que asume la responsabilidad por lo que dice y los invita a confiar en su sinceridad. La presunción de confianza no se reduce a una expectativa sobre la fiabilidad predecible del hablante, sino también comprende la confianza afectiva de los oyentes respecto de la sinceridad del hablante, ya que los oyentes tienen la expectativa de que el hablante tiene motivación para decir la verdad por la situación de dependencia informacional en la que ellos se encuentran, de manera que mantendrá las expectativas de los oyentes y responderá a esa confianza. Por eso, quien miente pretende ser sincero y asume cierta responsabilidad, pero realiza una triple manipulación: al apelar a la confianza afectiva de los oyentes, al amenazar con resentirse si no es creído y, finalmente, al pretender que la motivación de la confianza y la perspectiva del resentimiento justifican que los oyentes le crean (Faulkner, 2007). Este análisis de la mentira revisa la noción tradicional mediante una concepción más compleja de la intención de engañar (complex deceptionism, en la terminología de Mahon, 2015).

También Lackey (2013) considera que no se puede separar la mentira de la intención de engañar, ya que el engaño no consiste únicamente en generar una falsa creencia en alguien, sino también en la ocultación de información. Quien miente descaradamente o bajo coerción puede que no intente engañar, pero sí oculta información o, según Lackey, intenta ser engañoso. Por eso, cabe definir la mentira de modo que, en vez de incluir la intención de engañar, contemple el intento de ser engañoso: alguien mentiría a otra persona si y solo si enuncia algún contenido proposicional $p$, creyendo que es falso, e intenta ser engañoso con el oyente al decir que $p$ (Lackey, 2013).

Otra opción para eludir las complicaciones derivadas de la definición tradicional de la mentira consiste en renunciar a la intención de engañar, para caracterizar simplemente la mentira como el hecho de creer o pensar algo y, sin embargo, expresar otra cosa. Shibles (1988) siguió este camino, al considerar que todo lo relacionado con la intención de engañar concierne a los propósitos, efectos y concomitantes de la mentira, pero no a la definición del mentir. Para 
Shibles, mentir no equivale a hacer una afirmación falsa ni a decir algo distinto de la verdad objetiva o de lo que el común de la gente cree, sino a decir algo subjetivamente falso; por tanto, la mentira es subjetiva, ya que concierne a la creencia del hablante. Además, la mentira no se da de modo aislado, sino bajo la forma de una relación entre enunciados: se miente cuando hay contradicción entre lo que pensamos y lo que expresamos, al decir intencional o conscientemente algo que no concuerda con otro enunciado relativo a nuestra creencia. Esta concepción subjetiva de la mentira expande el rango de casos en que puede decirse que alguien miente, pues también contempla la mentira sobre la fuerza o extensión de nuestra creencia (al exagerar o mitigar), o bien la expresión poco clara o muy abstracta que oculta lo que creemos. Bajo esta concepción del mentir como expresión consciente de algo distinto de lo que creemos o pensamos, la mentira puede operar como dispositivo retórico o falacia informal, e involucra un contra-decir que socava la comunicación (Shibles, 1988). En suma, se trata de un análisis de la mentira que simplemente excluye la intención de engañar (simple non-deceptionism, según la denominación de Mahon, 2015), sin necesidad de restringir el mentir a la afirmación de un contenido proposicional que se asegura y hace valer.

La perspectiva de que la mentira no precisa de la intención de engañar puede asumir una forma más sofisticada. Carson (2010) ha definido la mentira como un enunciado deliberadamente falso para el cual el hablante aporta la garantía de que lo que dice es verdad; requiere la pretensión de garantizar la veracidad de lo enunciado por parte del hablante. Quien miente invita a los oyentes a confiar en lo que uno dice garantizando su verdad y, a la vez, viola una promesa implícita o una garantía de que habla con veracidad, por lo que se traiciona la confianza. Adicionalmente, Carson presta atención al contexto de enunciación y sostiene que, al mentir, el hablante enuncia algo en un contexto en el cual garantiza la verdad de lo que dice. La garantía aportada puede consistir no solo en algún tipo de promesa o fianza de que lo que uno dice es verdad, sino también en la presunción compartida o la convención respecto a que en cierto contexto rige la garantía de la verdad del enunciado (cosa que no ocurre al bromear, por ejemplo). Por eso, al garantizar la verdad de lo que se dice, el hablante promete tácita o explícitamente que cuanto dice es verdad, y esa garantía corre por defecto en la comunicación cotidiana. La mentira se da cuando el sujeto que habla enuncia algo en un con- 
texto en el cual garantiza la verdad de lo que dice, pero el hablante no asume que está garantizando la verdad de lo que dice a otra persona. Así, la mentira resultaría independiente de la intención de engañar, pues la garantía de la verdad no depende solo de las intenciones de quien habla ni de si acaso los oyentes creen que el hablante les garantiza la verdad de lo que dice (Carson, 2010, pp. 17-30).

De manera análoga, Shiffrin (2014) ha observado que la mentira se da cuando se realiza intencionalmente una aserción cuyo contenido el hablante no cree, en un contexto que manifiesta objetivamente la pretensión de que el enunciado se tome como representación verdadera de la creencia del hablante. Desde ese punto de vista, no hay mentira en aquellos contextos en que se encuentra suspendida la veracidad, en la medida en que la situación permite establecer que no se pretende decir la verdad (como en la ficción, el juego o el bromear); tampoco se miente cuando se da cierta falsificación de lo que se cree en contextos en que la posible insinceridad del hablante resulta razonable y justificada normativamente, como ocurriría en una mentira para salvar a un inocente (Shiffrin, 2014, pp. 12-19). Así pues, la mentira se distingue del engaño y no precisa de la intención de engañar, ya que el mentiroso no pretende inducir la formación de creencias en el oyente, sino formular aserciones insinceras en las que el hablante no cree (Shiffrin, 2014, pp. 19-21). Estamos ante concepciones de la mentira que reformulan la definición tradicional mediante una eliminación sofisticada de la condición de engaño (complex non-deceptionism, según Mahon, 2015).

Otro de los asuntos que ha generado posiciones divididas en el análisis filosófico actual de la mentira es la relación del mentir tanto con las máximas conversacionales que rigen en la pragmática de la comunicación cotidiana como con las implicaturas engañosas que se derivan de la explotación de esas máximas pragmáticas. Grice (2005) sostuvo que el significado de lo dicho involucra no solo las condiciones semánticas de verdad, sino también el significado intencionado por el hablante. Comprender el significado del hablante implica reconocer la intención subyacente a la comunicación. Además, Grice formuló un modelo de la conversación comunicativa que responde a cierto principio cooperativo e introduce cuatro máximas conversacionales: la cantidad (hacer contribuciones lo más informativas posible, y no decir más de lo informativamente necesario); la cualidad (no decir lo que se cree falso ni aquello que no se pueda probar adecuadamente); la relación (ser relevante e ir al grano); la del modo (evitar 
expresarse con oscuridad o ambigüedad; ser escueto y ordenado). Según Grice, el incumplimiento de alguna máxima genera implicaturas conversacionales, esto es, inferencias sobre la intención comunicativa en un contexto determinado y sobre el significado intencionado en el marco de la cooperación conversacional.

Al considerar la pragmática de la comunicación, Adler (1997) pudo argumentar que la mentira se relaciona en cierto modo con la implicatura falsa. La persona que miente engaña intencionalmente mediante la afirmación abierta de algo que el hablante cree falso y en la medida en que dirige una invitación al oyente para que acepte la verdad de su contribución engañosa. Por su parte, la implicatura engañosa exige tácitamente del oyente que colabore en su propio engaño al realizar las inferencias que lo despistan, pero también constituye una invitación a que el oyente acepte lo que dice el hablante, pues el singificado intencionado de este último incorpora las máximas conversacionales; de ese modo, se quiebra la confianza comunicativa mediante la explotación de las lagunas de comprensión asociadas a las inferencias del oyente. En suma, el engaño mediante la explotación de las máximas conversacionales con implicaturas falsas daña la expectativa de veracidad y sinceridad, pues suministra subterfugios y rodeos para que el hablante se salga con la suya sin poder ser culpado (Adler, 1997).

Algunas aproximaciones a la mentira han analizado el mentir como un intento intencional y explícito de comunicar algo que el hablante cree falso, en un contexto sujeto a una norma conversacional (que no hay que decir enunciados que el hablante crea falsos) que quien habla pretende violar (comunicando algo falso). Matizando este análisis, cabría sostener que la mentira no exigiría rigurosamente creer que la norma que prohíbe comunicar algo falso está vigente en efecto, o bien que se intente violar esta norma, como revela la mentira infantil (Fallis, 2012). En ese sentido, la caracterización pragmática de la mentira podría concebirla como una aserción insincera que viola la máxima conversacional de que no hay que decir lo que crees que es falso (Meibauer, 2018).

Desde una perspectiva pragmática centrada en las máximas y en las implicaturas conversacionales, se puede distinguir nítidamente la mentira, en que el hablante cree que lo que dice es falso y, por otra parte, aquellos enunciados cuyo significado literal es verdadero para el hablante, pero que invitan al oyente a realizar inferencias falsas por medio de la violación de las máximas o de implicaturas que explotan las normasconversacionales. Además, un análisis pragmático permite 
diferenciar una serie de fenómenos relacionados con el engaño verbal: la mentira involucra la violación de la máxima de cualidad según la cual el hablante ha de ser veraz; la charlatanería consistiría en una violación de la máxima conversacional de cualidad que requiere no decir nada que no sea susceptible de comprobación; la mentira descarada (bald-faced lie) consistiría en una explotación de la máxima conversacional de cualidad según la cual no hay que decir nada falso; la retención u omisión de información constituiría una violación de una máxima conversacional de cantidad, que nos exige aportar la información requerida por los objetivos del intercambio comunicativo en curso; por último, el engaño sin mentira correspondería a una violación de la máxima conversacional de cantidad, o bien de las violaciones de las máximas de relación y modo que exigen ser pertinente, ordenado, escueto y claro, pero también podría involucrar la explotación de diversas máximas conducentes a implicaturas falsas (Dynel, 2011).

Si bien parece compartir la concepción tradicional de la mentira como un abuso inherente de la afirmación, al realizar una aserción cuyo contenido el hablante considera falso, Williams (2002) planteó algunas precisiones sobre el concepto que permiten repensar a fondo el problema de la mentira. El presupuesto del análisis de Williams es que en nuestras prácticas sociales existen dos virtudes relacionadas con la verdad: sinceridad y precisión. La sinceridad consiste en decir lo que se cree verdadero, y resulta esencial para la transmisión y preservación de la verdad; la precisión (accuracy) involucra un particular cuidado, exactitud y fiabilidad al buscar la verdad. La veracidad (truthfulness) combina las virtudes de la sinceridad y la precisión, de modo que la persona veraz dice lo que cree y se preocupa de que sus creencias sean válidas (Williams, 1996).

En todo caso, Williams considera que la disposición a la sinceridad se ve matizada por la confianza y la confiabilidad que rigen en las relaciones sociales, y pueden variar de acuerdo con las circunstancias históricas. Aunque se supone que la aserción pretende comunicar creencias, responder a la confianza y generar creencias en el oyente, la creencia se puede expresar de manera vaga, figurativa o con implicaturas conversacionales sin las cuales no se comprendería cabalmente el sentido de una expresión. Por eso, no solo la mentira abusa de la aserción: un rasgo del lenguaje es que el hablante puede comunicar contextualmente más de lo que dice explícitamente en el contenido proposicional de una afirmación; y también hay un abuso en la explotación deliberada del modo en que se pretende 
que el oyente entienda un enunciado. En ese sentido, resulta sumamente razonable la acusación que Williams dirige a la concepción tradicional de la mentira: fetichiza la aserción, al aislarla del contexto en que opera y al endosarle todas las exigencias de confiabilidad. Ahora bien, las relaciones de confiabilidad y el grado en que las personas han de atender al contexto y a las presuposiciones contextuales varían situacional e históricamente. En qué medida haya que atender a presuposiciones e implicaturas no depende solamente del contenido de una aserción, sino también del tipo de relación comunicativa y de las expectativas de los interlocutores, que varían entre contextos de cooperación conversacional, contextos agonísticos de competencia regulada, contextos de engaño estratégico, en culturas de la vergüenza y del honor, etc. En suma, la veracidad y la sinceridad son disposiciones que no pueden interpretarse como el seguimiento de una única regla (no decir una mentira), pues se centran en el desarrollo y mantenimiento de relaciones con los otros, bajo distintas clases y grados de confianza (Williams, 2002, pp. 84-122). Así pues, un análisis adecuado de la mentira debiera considerar el carácter escalar de la enunciación no veraz, a saber: la existencia de diferentes niveles de precisión y distintos grados de creencia, de compromiso epistémico y de confianza, de manera que solo en ciertos contextos la mentira concierne a la aseveración de un contenido proposicional que se cree falso (Meibauer, 2018).

\section{Premisas para una caracterización lexicográfica de la mentira}

A PESAR DE LA CONSTANTE TENTACión de aportar una definición unívoca y categórica de la mentira, así como de cierta propensión a fetichizar el enunciado mentiroso, la tradición filosófica nos aporta relevantes indicaciones para pensar actualmente las condiciones del mentir. Para concebir adecuadamente las múltiples facetas de la mentira, es conveniente tener presentes algunos hitos analíticos que no siempre se han integrado en la teoría tradicional de la mentira. En primer lugar, resulta fundamental reformular la distinción entre decir una mentira y mentir (Montaigne, 1998), si es que pretendemos llevar a cabo un análisis no reductivo de las condiciones de la mentira, que abarque una diversidad de contextos y condiciones de realización. Podemos aventurar que la definición tradicional de la mentira como aserción insincera, o bien como enunciado que se cree falso y que se dice con intención de engañar, da cuenta básicamente de decir una mentira, 
pero no describe la gramática profunda del mentir en un sentido más amplio y prototípico, como aquel que se articula en la comprensión cotidiana y en sus múltiples recursos idiomáticos para nombrar situacionalmente la mentira. En segundo lugar, hay que evitar la fetichización del enunciado mentiroso, ya que, para la comprensión de la mentira, se ha de atender a los contextos específicos y presupuestos contextuales bajo los cuales se miente, así como a los entornos de confianza comunicativa y a las expectativas intersubjetivas que enmarcan la atribución cotidiana de la mentira. En tercer lugar, es razonable una aproximación escalar de la mentira, pues estamos ante un fenómeno que se presenta en distintos contextos comunicativos y que ocurre en diferentes grados, según las expectativas de veracidad o sinceridad, pero también del grado de fiabilidad y precisión exigido en cada caso. $Y$ es que no cabe esperar los mismos niveles de confiabilidad interpersonal ni de fiabilidad epistémica en un tribunal o en un informe de laboratorio (contextos en los que se espera que se diga la verdad, toda la verdad y nada más que la verdad) que en una discusión de café o en la charla cotidiana.

Si abordamos la mentira como una categoría prototípica que cubre distintas instancias relacionadas en virtud de parecidos de familia, es preciso describir correctamente los marcos situacionales y guiones específicos que dan forma a la gramática profunda de cada expresión de la mentira. En ese caso, no podemos desconocer que el estado epistémico del sujeto enunciador resulta importante para concebir las condiciones contextuales de la mentira: al mentir, no es lo mismo no tener una creencia sobre un estado de cosas, creer que no se da un estado de cosas, no saber si se da un estado de cosas o saber que no se da un estado de cosas. No en vano, quien miente al decir $p$, no creyendo que se da ese estado de cosas, creyendo que no se da o no sabiendo si se da $p$, solo deniega su creencia con su enunciado, y miente en un sentido débil; pero el que miente sabiendo que no se da el estado de cosas sobre el cual enuncia lo contrario de lo que cree, contradice lo que cree y los hechos, de manera que miente en sentido fuerte, y compromete tanto su sinceridad como su fiabilidad epistémica. Tampoco es lo mismo mentir simplemente al decir algo distinto de lo que se cree sobre un estado de cosas (o sea, al tergiversar una creencia), o bien formular una mentira de segundo orden al declarar la verdad de un enunciado que el hablante considera no verdadero o cree que es falso (invirtiendo los valores veritativos atribuidos en un juicio de verdad). 
En fin, los tipos de relación fenomenológica con el contenido epistémico son parte esencial de una descripción rigurosa de la gramática profunda del mentir. Asimismo, no resulta fenomenológicamente indiferente el formato de expresión en la enunciación de la mentira: si acaso se manifiesta indicativamente lo contrario de lo que se cree o siente, o bien se afirma como aserto con un contenido proposicional definido; si se miente al decir lo contrario de lo que se cree, o bien al exagerar o mitigar algunos aspectos en la expresión de la creencia; si se trata de decir una mentira discreta o de desarrollar un argumento falaz o un relato mistificador; si se miente al falsificar el contenido proposicional de nuestra creencia, o bien mediante la tergiversación del marco comunicativo, la comprensión compartida y los presupuestos contextuales de la enunciación. En ese sentido, existen mentiras del enunciado (que conciernen a lo dicho) y mentiras de la enunciación (vinculadas al modo de decir y al marco discursivo).

Para describir correctamente la compleja gramática de la mentira, también resulta importante dar cuenta del propósito inherente a cada forma específica de mentir en un contexto determinado. Como muy bien entendieron Chisholm y Feehan (1977), la intención de engañar al mentir puede consistir en a) un intento positivo y directo de causar la creencia de que $p$ en el oyente, b) un intento positivo e indirecto de contribuir a que el oyente mantenga una creencia de que $p$, c) un intento directo y negativo de eliminar una creencia del oyente de que no $p, \mathrm{~d}$ ) un intento indirecto y negativo de evitar que el oyente adquiera cierta creencia de que no $p$; también hay intentos de engañar por omisión, como e) el propósito directo y positivo de permitir que el oyente adquiera la creencia de que $p, \mathrm{f})$ el propósito indirecto y positivo de permitir que el oyente continúe sosteniendo la creencia de que $p, \mathrm{~g}$ ) el propósito directo y negativo de permitir que el oyente deje de creer que no $p$, y, por último, h) el propósito indirecto y negativo de permitir que el oyente siga sin creer que no $p$. De ese modo, el propósito inherente a cada contexto de la mentira califica el grado en que se miente, el nivel de expectativas y la gravedad atribuida a la mentira; y es que el engaño al mentir no consistiría solo en la intención de engañar directa y positivamente, ya que cubre todo un abanico de opciones.

Adicionalmente, la descripción adecuada de la gramática inherente a cada contexto en que se miente involucra prestar atención al propósito interpersonal que se proyecta en cada caso y al beneficio o daño proyectado (independientemente 
de las consecuencias que resulten efectivamente al mentir). Cabe concebir diferentes escenarios posibles, dependiendo de si la mentira favorece o perjudica al hablante, al oyente o a terceras personas, o bien, la mentira pretende favorecer al hablante y perjudica al oyente y a terceras personas; incluso la mentira presuntamente pura, expresada por el puro deleite de mentir, o bien aquella que solo pretende embelesar en la conversación, involucran una intención de beneficio personal por parte del hablante o en beneficio de la relación comunicativa con los oyentes. Pese a que algunas teorías tradicionales de la mentira han considerado irrelevante la consideración de sus repercusiones interpersonales, cada uno de los propósitos interpersonales proyectados permite reconocer una gramática distinta para el mentir, y matiza la atribución de la mentira.

La consideración de la mentira como una categoría prototípica que se realiza matizada y escalarmente en distintos contextos de enunciación (y no se reduce a la afirmación no veraz del contenido proposicional de un enunciado aislado) aparece plasmada en esa cristalización de la intuición lingüística de los hablantes y del uso idiomático habitual que es la definición de diccionario. El Diccionario de la lengua española define la mentira en un sentido amplio y prototípico como la "expresión o manifestación contraria a lo que se sabe, se piensa o se siente" (Real Academia Española, 2014). La definición apunta a una amplia gama de acepciones y realizaciones del significado: a) la mentira puede darse en la manifestación o la expresión, de modo que cubre los casos de la enunciación declarativa, la exposición pública o el dar a conocer algo, ya sea mediante palabras o gestualmente; b) "expresar lo contrario" puede consistir en decir lo opuesto y lo que contradice cierta creencia, pero también en manifestar aquello que se muestra completamente diferente o se sitúa en el extremo opuesto; por último, c) se puede manifestar no solo lo contrario de lo que se sabe, sino también de lo que se piensa o se siente, de manera que se puede tergiversar alguna opinión o juicio, así como lo que uno experimenta, además de aquello que se conoce, de lo cual se tiene información o eso de lo que se tiene certeza.

Esta caracterización lexicográfica se aproxima a la concepción filosófica de la mentira que excluye simplemente la intención de engañar (simple nondeceptionism, en la terminología de Mahon, 2015). Sin embargo, lo más relevante de esta cristalización lexicográfica de la comprensión lingüística cotidiana de la mentira radica en que ya no persigue estipular un patrón conceptual único o 
un estándar exclusivo de condiciones necesarias y suficientes (como ocurre en los análisis lógico-lingüísticos), sino que nos permite reconocer toda una matriz de parecidos de familia entre diferentes realizaciones contextuales del mentir, la cual se sustenta en una flexible categorización prototípica de la mentira. Así, los análisis conceptuales de la mentira como afirmación no veraz de lo que se cree falso corresponden únicamente a una definición de la forma compleja decir una mentira, pero no consiguen agotar las acepciones del mentir o de la mentira en nuestro lenguaje natural.

En un segundo ejercicio de descripción lexicográfica de la mentira como categoría prototípica, realizada de modo matizado en distintos contextos de enunciación, cabe realizar una indagación inversa de aquellos términos del diccionario en que la mentira aparece como parte del definiens, y también podemos registrar las diferencias de significado introducidas por los distintos sinónimos de mentira. En ambos casos, logramos precisar algunas diferencias de sentido entre términos con una referencia semejante, que conciernen a los distintos contextos de realización de la mentira. Si dejamos a un lado los múltiples términos coloquiales con los cuales se designa la mentira en diferentes países hispanohablantes, hay algunas entradas del Diccionario de la lengua española que incluyen el término mentira en la definición, pero matizan el modo de realización de la mentira. Por ejemplo, el embuste se define como una "mentira disfrazada con artificio"; el embeleco, como un "embuste"; la coba, como un "embuste gracioso" y un "halago y adulación fingidos"; la fábula, como una "relación falsa, mentirosa, de pura invención" y como una "ficción artificiosa con que se encubre o disimula una verdad"; la falacia, como un "engaño, fraude o mentira con que se intenta dañar a alguien"; el infundio, como una "mentira, patraña o noticia falsa, generalmente tendenciosa” (Real Academia Española, 2014). Algunas de las entradas enfatizan el carácter artificioso y construido de la mentira; en otros casos, se destaca el efecto halagador sobre el oyente, o bien, el intento de perjudicarlo.

Por otra parte, si atendemos a aquellas entradas en el diccionario cuya definición cae bajo las características atribuidas a la mentira ("expresión o manifestación contraria a lo que se sabe, se piensa o se siente”), podríamos considerar que hay mentira en la calumnia, en tanto que "acusación falsa, hecha maliciosamente para causar daño"; también en la fanfarronería, en tanto que "modo de hablar 
y portarse de los fanfarrones", o sea, de quien "se precia y hace alarde de lo que no es"; en el fraude, como "acción contraria a la verdad y a la rectitud, que perjudica a la persona contra quien se comete"; en la hipocresía, como "fingimiento de cualidades o sentimientos contrarios a los que verdaderamente se tienen o experimentan"; en la impostura, como "fingimiento o engaño con apariencia de verdad"; o bien en la patraña, como "invención urdida con propósito de engañar” (Real Academia Española, 2014).

El ejercicio de fenomenología lingüística implicado en la caracterización lexicográfica se completa al examinar los sentidos de los sinónimos de mentira en algún diccionario: bulo se asocia a un "rumor público falso"; paparrucha se emplea "si el disfraz es burdo o la expresión es familiar", especialmente "cuando el asunto es poco importante o despreciable"; términos como fraude, superchería, embeleco o falacia "suponen intención de aprovecharse de la mentira"; la engañifa connota una falsedad de poca monta con intención de burla, así como la farsa sugiere un "engaño prolongado"; por último, patraña y cuento serían "mentiras de pura invención imaginativa” (Blecua, 2002, pp. 432-433). En suma, cabría pensar que la familia semántica de la mentira se ordena en virtud de dimensiones como: a) la magnitud del engaño y la elaboración de la invención, b) la modalidad de tergiversación (orientada a la autoexhibición o la seducción, a la simulación o al disimulo) y, por último, c) el propósito de la manipulación de las impresiones (aprovechamiento o daño).

4. A modo de conclusión: la trama de la mentira y el sentido de la posverdad

SI LA TRADICIÓN FILOSÓFICA aporta valiosas consideraciones morales sobre el mentir, y si el análisis conceptual lógico-lingüístico proporciona una delimitación precisa de las condiciones necesarias y suficientes que concurren al decir una mentira, la descripción lexicográfica suministra vívidas caracterizaciones de las intuiciones de los hablantes y de su comprensión idiomática cotidiana, tal como se dan en la designación de alguna de las matizadas realizaciones contextuales de la mentira, prototípicamente entendida como la expresión o manifestación de lo contrario a lo que se cree, sabe o experimenta. De ese modo, el ejercicio de fenomenología lingüística implícito en la descripción lexicográfica enriquece 
sustantiva y situacionalmente los análisis de las condiciones formales que se dan al afirmar una mentira aislada.

En este trabajo hemos recogido algunas perspectivas filosóficas tradicionales que reflexionaron sobre dimensiones morales de la mentira como la intención moral de engañar o la afectación del derecho a saber de los interlocutores, pero también aquellas que llamaron la atención sobre la gran variedad de realizaciones del mentir, las cuales desbordan el simple acto discreto de decir una mentira. También los análisis conceptuales de la mentira nos han entregado guías valiosas para entender las condiciones de enunciación de una mentira, aunque los acercamientos analíticos suelen concentrarse sobre todo en los requisitos formales para la aseveración o afirmación (assertion) de cierto contenido proposicional aislado que el hablante cree falso, en desmedro de la intención de engañar o de las circunstancias de la mentira. Quizá, los más fértiles análisis conceptuales de la mentira sean aquellos que exploran los marcos comunicativos que impugna quien dice una mentira, ya se trate de las garantías de veracidad, de las expectativas interpersonales de confiabilidad, o bien de los contextos de justificación racional de nuestras pretensiones de validez. Frente a la tentación analítica de fetichizar la afirmación aislada de una mentira como paradigma exclusivo del mentir y del engaño verbal (como si la mentira fuese categóricamente atribuible), hemos apostado por la descripción lexicográfica como marco para caracterizar prototípicamente la mentira y para dar cuenta escalarmente de las principales dimensiones de realización del mentir: los distintos niveles del artificio inventivo, las diferentes modalidades de tergiversación, así como las variadas propuestas de manipulación comunicativa y de afectación de los interlocutores.

La revisión bibliográfica y la descripción fenomenológica de las conceptualizaciones teóricas y cotidianas de la mentira nos permiten concluir que existe una diferencia decisiva entre los marcos y condiciones en que se dice una mentira y aquellos en que se miente. Adicionalmente, se pueden marcar rasgos distintivos de la posverdad como un tipo de régimen enunciativo de la mentira, caracterizado por la instrumentalización de la desregulación informativa y la indiferencia veritativa, al servicio de la manipulación de los públicos. En la tabla 1, se representa nuestra posición respecto a la relación entre la mentira declarativa, el mentir de la enunciación y la posverdad. 
Tabla 1. Rasgos de la mentira del enunciado, del mentir y de la posverdad

\begin{tabular}{|c|c|c|c|}
\hline & $\begin{array}{l}\text { Decir una } \\
\text { mentira }\end{array}$ & Mentir & $\begin{array}{l}\text { Régimen de } \\
\text { posverdad }\end{array}$ \\
\hline $\begin{array}{l}\text { Tipo de } \\
\text { mentira }\end{array}$ & $\begin{array}{l}\text { Mentira del } \\
\text { enunciado }\end{array}$ & $\begin{array}{l}\text { Mentira de la } \\
\text { enunciación }\end{array}$ & $\begin{array}{l}\text { Metamentira o } \\
\text { posmentira }\end{array}$ \\
\hline Formato & Declarativo & Multimodal & Multimediático y viral \\
\hline $\begin{array}{l}\text { Condición } \\
\text { suficiente }\end{array}$ & Falsedad & Engaño & $\begin{array}{l}\text { Multiplicación de } \\
\text { versiones y burbujas } \\
\text { informacionales }\end{array}$ \\
\hline $\begin{array}{l}\text { Condición } \\
\text { necesaria }\end{array}$ & Engaño & Falsedad & $\begin{array}{l}\text { Relativización de la } \\
\text { verdad e indiferencia } \\
\text { veritativa }\end{array}$ \\
\hline $\begin{array}{l}\text { Tipo de } \\
\text { falsificación }\end{array}$ & $\begin{array}{l}\text { Falsificación de } \\
\text { la creencia }\end{array}$ & $\begin{array}{l}\text { Falsificación } \\
\text { representacional }\end{array}$ & $\begin{array}{l}\text { Falsificación de } \\
\text { la pretensión de } \\
\text { validez y del marco } \\
\text { comunicativo }\end{array}$ \\
\hline $\begin{array}{l}\text { Tipo de } \\
\text { efectuación } \\
\text { pragmática }\end{array}$ & $\begin{array}{l}\text { Violación de } \\
\text { la máxima } \\
\text { cualitativa de } \\
\text { veracidad }\end{array}$ & $\begin{array}{l}\text { Violación de } \\
\text { las máximas de } \\
\text { cantidad, relación } \\
\text { y modo }\end{array}$ & $\begin{array}{l}\text { Violación o } \\
\text { explotación } \\
\text { variables de las } \\
\text { distintas máximas } \\
\text { conversacionales }\end{array}$ \\
\hline $\begin{array}{l}\text { Modo de } \\
\text { atribución }\end{array}$ & Categórica & Prototípica & Instrumental \\
\hline $\begin{array}{l}\text { Implicación } \\
\text { moral }\end{array}$ & $\begin{array}{l}\text { Cuestionamien- } \\
\text { to de la veracidad } \\
\text { epistémica }\end{array}$ & $\begin{array}{l}\text { Cuestionamiento } \\
\text { de la credibilidad } \\
\text { comunicativa }\end{array}$ & $\begin{array}{l}\text { Cuestionamiento de la } \\
\text { confianza social }\end{array}$ \\
\hline $\begin{array}{l}\text { Ejemplos de } \\
\text { realización } \\
\quad \text { social }\end{array}$ & $\begin{array}{l}\text { Falso testimonio } \\
\text { o fraude } \\
\text { científico }\end{array}$ & $\begin{array}{l}\text { Simulación, } \\
\text { disimulación, } \\
\text { impostura o } \\
\text { hipocresía }\end{array}$ & $\begin{array}{l}\text { Bulos, infundios o } \\
\text { charlatanería }\end{array}$ \\
\hline
\end{tabular}

Fuente: elaboración propia. 
Así pues, estamos en condiciones de retomar la pregunta planteada al comienzo de este texto y podemos discutir con fundamento la forma de tergiversación comunicativa asociada a la posverdad. Las formas actuales de falsificación de las noticias, de circulación de bulos y de reproducción mediática de charlatanería sin ningún compromiso veritativo no parecen concordar con las condiciones formales exigidas para que pueda hablarse de la afirmación o aseveración de una mentira discreta. Sin embargo, si concebimos la mentira en sentido prototípico y nos atenemos a la descripción lexicográfica de la terminología del mentir, la llamada posverdad concuerda con una forma generalizada, masiva, instrumental y desregulada de ejercicio de la mentira, mediante distintos mecanismos de tergiversación y bajo diversos propósitos de manipulación de los interlocutores, pero también a través de diferentes modos de impugnación de las garantías, los compromisos epistémicos, o los contextos de justificación de pretensiones de validez comunicativa.

Aunque no consiste en decir simplemente algunas mentiras aisladas, la posverdad constituye una consagración del mentir en plural, un régimen de desregulación de la tergiversación, que capitaliza el carácter proteico y multiforme de la mentira en nuestra comprensión cotidiana, y lo multiplica instrumentalmente bajo formas mediáticas y reticulares de tramado ficcional, reproducción indiferente y consumo masivo. Si bien cabe concebir este escenario de la posverdad como una segmentación de burbujas informacionales y una descomposición de los juegos de verdad en la economía de la comunicación contemporánea, también podemos describirlo como una instrumentalización escalar y desregulada de las múltiples facetas de la mentira. Así, la posverdad multiplicaría las metamentiras (mentiras de segundo orden, que desmienten lo que se quiere decir) y posmentiras (mentiras indiferentes a las condiciones de veredicción). No parece atribuible categóricamente, e incluso cuestiona los marcos convencionales de atribución prototipica del mentir; bajo la posverdad, la mentira se atribuye instrumentalmente a distintas versiones, en función de la necesidad de autoafirmación y manipulación de los públicos segmentados. Con esta caracterización de la posverdad remarcamos los crecientes riesgos epistémicos, morales y políticos de la manipulación reticular, de la capitalización del engaño, del descrédito universal y de la falta generalizada de confianza comunicativa e interpersonal. 
Adler, J. E. (1997). Lying, Deceiving, or Falsely Implicating. The Journal of Philosophy, 94(9), 435-452.

Ball, J. (2017). Post-Truth: How Bullshit Conquered the World. London: Biteback Publishing.

Black, M. (1982). The Prevalence of Humbug. Philosophical Exchange, 13(1), artículo 4. Recuperado de https://digitalcommons.brockport.edu/phil_ex/ vol13/iss $1 / 4$

Blecua, J. M. (Dir.). (2002). Diccionario avanzado de sinónimos y antónimos de la lengua española. Barcelona: VOX.

Bok, S. (1979). Lying: Moral Choice in Public and Private Life. New York: Vintage Books.

Carson T. L. (2010). Lying and Deception: Theory and Practice. New York: Oxford University Press.

Chisholm, R. M., \& Feehan, T. D. (1977). The Intent to Deceive. The Journal of Philosophy, 74(3), 143-159.

Cooke, N. A. (2017). Posttruth, Truthiness, and Alternative Facts: Information Behavior and Critical Information Consumption for a New Age. Library Quarterly: Information, Community, Policy, 87(3), 211-221.

Cruz, M. (2017). La posverdad: entre la falsedad y el engaño. Uno, 27, 29-30.

D’Agostini, F. (2013). Mentira. Buenos Aires: Adriana Hidalgo Editora.

Dynel, M. (2011). A Web of Deceit: A Neo-Gricean View on Types of Verbal Deception. International Review of Pragmatics, 3, 139-167.

Fallis, D. (2012). Lying as a Violation of Grice's First Maxim of Quality. Dialectica, 66(4), 563-581.

Faulkner, P. (2007). What is Wrong with Lying? Philosophy and Phenomenological Research, 75(3), 524-547.

Frankfurt, H. G. (2006). On Bullshit. Sobre la manipulación de la verdad. Barcelona: Paidós.

Grice, H. P. (2005). Lógica y conversación. En: L. M. Valdés Villanueva (Comp.) La búsqueda del significado. Lecturas de Filosofia del lenguaje ( $4^{\mathrm{a}} \mathrm{ed}$.) (pp. 491-519). Madrid: Tecnos.

Grocio, H. (1925). Del derecho de la guerra y de la paz (Vol. III). Madrid: Reus. 
Harsin, J. (2015). Regimes of Posttruth, Postpolitics, and Attention Economies. Communication, Culture \& Critique, 8, 327-333.

Kant, I., \& Constant, B. (2012). ¿Hay derecho a mentir? (La polémica Immanuel Kant-Benjamin Constant sobre la existencia de un deber incondicionado de decir la verdad). Madrid: Tecnos.

Keyes, R. (2004). The Post-Truth Era: Dishonesty and Deception in Contemporary Life. New York: St. Martin's Press.

Lackey, J. (2013). Lies and Deception: An Unhappy Divorce. Analysis, 73(2), 236-248.

Mahon J. E. (2015). The Definition of Lying and Deception. En: E. N. Zalta (Ed.). The Stanford Encyclopedia of Philosophy. Recuperado de: http://plato. stanford.edu/entries/lying-definition/

Meibauer, J. (2018). The Linguistics of Lying. Annual Review of Linguistics, 4, 357-375.

Montaigne, M. (1992). De los mentirosos. En: Ensayos (Vol. I) (pp. 69-74). Madrid: Cátedra.

Montaigne, M. (1998). Del mentir. En: Ensayos (Vol. II) (pp. 414-419). Madrid: Cátedra.

Real Academia Española (2014). Diccionario de la lengua española (23a ed.). Madrid: Espasa.

San Agustín (1954). Sobre la mentira. En: Obras de San Agustín, Tratados morales (Vol. XII) (pp. 529-609). Madrid: Biblioteca de Autores Cristianos.

Shibles, W. (1988). A Revision of the Definition of Lying as an Untruth Told with Intent to Deceive. Argumentation, 2, 99-115.

Shiffrin, S. V. (2014). Speech Matters. On Lying, Morality and the Law. Princeton: Princeton University Press.

Sorensen, R. (2010). Knowledge-lies. Analysis, 70(4), 608-615.

Williams, B. (1996). Truth, Politics, and Self-Deception. Social Research, 63(3), 603-617.

Williams, B. (2002). Truth and Truthfulness: An Essay in Genealogy. Princeton: Princeton University Press. 